\title{
EDITORIAL
}

\section{Adrenomedullin: a smart road from pheochromocytoma to treatment of pulmonary hypertension}

\author{
M. Westphal*, M. Booke\#, A.T. Dinh-Xuan
}

In 1993, KITAMURA et al. [1] isolated a new peptide from human pheochromocytoma cells, stimulating cAMP production in human platelets and inducing systemic hypotension in rats. Due to its origin of discovery, i.e. the medulla of the adrenal gland, it was named adrenomedullin [1]. Adrenomedullin is a 52-amino acid peptide hormone with structural homology to calcitonin gene-related peptide [2]. Together with pro-adrenomedullin N-terminal 20-peptide, adrenomedullin is generated by post-translational splicing from its precursor, pro-adrenomedullin [3]. Initially, it was believed that adrenomedullin is only expressed in tumour cells, but subsequent studies revealed that it is a multifunctional peptide, synthesised by a huge variety of mammalian tissues, including myocardium, central nervous system, kidney, and reproductive and digestive organs [2, 4]. In addition, adrenomedullin is produced by endothelial and smooth muscle cells of both the systemic and pulmonary circulation [5]. Adrenomedullin regulates cardiopulmonary functions and vascular tone as both a circulating hormone and as a local autocrine/ paracrine mediator [6].

The haemodynamic effects of adrenomedullin are predominantly mediated by cAMP production resulting from activation of two Gs-protein-coupled plasma membrane receptors of the calcitonin peptide family: the calcitonin receptor-like receptor and the receptor activity-modifiying protein-2 or -3 [2]. Moreover, adrenomedullin mediates smooth muscle cell hyperpolarisation by activating ATPsensitive $\mathrm{K}^{+}$channels [7], stimulates the release of vasodilatory prostaglandins [8], and elicits endothelium-dependent vasorelaxation secondary to nitric oxide (NO) formation $[8,9]$.

Inasmuch as adrenomedullin reduces pulmonary vascular tone and improves tissue oxygenation [10], supplementation of exogenous adrenomedullin may be a rationale in the management of acute respiratory distress syndrome (ARDS) associated with pulmonary hypertension. When discussing the usefulness of intravenous adrenomedullin infusion to treat pulmonary hypertension, it has to be taken into consideration that the effects are not restricted to the pulmonary circulation. Another important effect of adrenomedullin is the decrease in peripheral vascular resistance and the ensuing reduction in afterload, which may stimulate heart rate and cardiac output via reflex mechanisms [11]. In a recent study by WestPHAL et al. [12], the effects of exogenous adrenomedullin infusion on systemic and pulmonary haemodynamics were investigated in endotoxaemic sheep. While adrenomedullin reduced the endotoxaemia-associated pulmonary vasopressive

*Dept of Anesthesiology and Intensive Care, University of Muenster, Muenster, "Dept of Anesthesiology, Klinikum des MTK, Bad Soden, Germany. 'Service de Physiologie-Explorations Fonctionnelles, Hôpital Cochin, Paris, France.

Correspondence: M. Westphal, Dept of Anesthesiology and Intensive care, University of Muenster, Albert-Schweitzer-Str. 33, 48149, Muenster, Germany. Fax: 49 2518348667. E-mail: Martin.Westphal@gmx.net effect, it aggravated the hypotensive-hyperdynamic circulatory state [12], a side-effect that may limit its clinical use in sepsis.

In the current issue of the European Respiratory Journal $(E R J)$, VON DER HARDT et al. [13] report the results of a carefully conducted study on the effects of aerosolised adrenomedullin on pulmonary hypertension in a surfactantdepleted piglet model. The major finding was that nebulisation of adrenomedullin $\left(50 \mathrm{ng} \cdot \mathrm{kg}^{-1} \cdot \mathrm{min}^{-1}\right.$ for $\left.2 \mathrm{~h}\right)$ resulted in a sustained reduction in mean pulmonary arterial pressure (MPAP). While systemic blood pressure decreased only to a clinically insignificant extent, no changes occurred in systemic vascular resistance, heart rate and cardiac index [13]. The study by VON DER HARDT et al. [13] is one of the first to have demonstrated that this route of adrenomedullin administration is a simple approach to effectively treat pulmonary hypertension while minimising the risk of systemic side-effects.

NAGAYA et al. [14] have also performed long-term studies in this area and demonstrated that repeated inhalation of adrenomedullin $\left(5 \mu \mathrm{g} \cdot \mathrm{kg}^{-1}\right.$ over $\left.30 \mathrm{~min}\right)$ in rats ameliorates monocrotaline-induced pulmonary hypertension without affecting systemic haemodynamics. Apart from a long-lasting reduction in MPAP and pulmonary vascular resistance (PVR), adrenomedullin also attenuated the increase in medial wall thickness of peripheral pulmonary arteries and improved survival [14]. Furthermore, NAKANISHI et al. [15] demonstrated that experimental pulmonary hypertension in rats induced by a hypobaric hypoxic environment is associated with markedly increased adrenomedullin concentrations in both plasma and heart tissue. The abovementioned studies support the assumption that upregulation of adrenomedullin plays a protective role in the pathogenesis of pulmonary hypertension. In conditions, where this adaptive mechanism fails over time, exogenous adrenomedullin substitution, therefore, appears to be a causative treatment strategy. When comparing adrenomedullin with alternative clinical approaches, such as inhalation of NO or nebulisation of prostaglandins, adrenomedullin might be superior due to its long-lasting effect. However, the absence of direct comparisons between these compounds renders the answer to this very interesting question elusive.

There are also some clinical data supporting the use of adrenomedullin in the common setting of pulmonary hypertension. Similarly to what has been observed in animal studies [12], intravenous infusion of adrenomedullin in patients with pulmonary hypertension contributed to a reduction in vascular resistance of both the systemic and pulmonary circulation [16]. Recently, NAGAYA et al. [17] have provided evidence that intratracheal delivery of aerosolised adrenomedullin $\left(10 \mu \mathrm{g} \cdot \mathrm{kg}^{-1}\right)$ has likewise beneficial effects in patients with idiopathic pulmonary hypertension. Notably, adrenomedullin nebulisation resulted in a significant decrease in both MPAP and PVR without impacting on systemic blood pressure and heart rate. In addition, inhalation of 
adrenomedullin improved exercise capacity, as indicated by improved global oxygen transport. Therefore, it appears that the current literature on this topic, although limited in extent, supports the view that adrenomedullin is a promising adjunct in the therapeutic armament targeting the treatment of pulmonary hypertension, independent of its pathogenesis.

Another interesting and important finding by VON DER HARDT et al. [13] is the observation that aerosolisation of adrenomedullin reduced endothelin (ET)-1 mRNA in lung tissue and ET-1 protein expression in endothelial cells of pulmonary arteries. Since ET-1 is a potent pulmonary vasoconstrictor, implicated in a broad spectrum of pulmonary disorders associated with pulmonary hypertension [18], adrenomedullin inhalation seems to be a goal-directed approach in this setting. Previously, the current authors reported an adrenomedullin-associated improvement in tissue oxygenation in pulmonary hypertensive piglets that was linked with a likewise reduction in both lung tissue ET-1 content and MPAP [10]. In this regard, it is important that (ARDS-derived) tissue hypoxia represents a compelling stimulus to upregulate adrenomedullin receptor function [19]. In addition, it has to be taken into account that pulmonary hypertension per se impairs hypoxic pulmonary vasoconstriction (HPV), which in turn contributes to a mismatch between ventilation and perfusion [20]. Therefore, it is conceivable that the adrenomedullin-associated reduction in MPAP restores HPV, thereby minimising pulmonary shunting and improving tissue oxygenation.

Interestingly, the adrenomedullin-linked amelioration in pulmonary hypertension was accompanied by a $30 \%$ reduction in interleukin (IL)-1 $\beta$ gene expression in lung tissue [13]. In agreement with VAN DER VARDT et al. [13], other investigators have reported an anti-inflammatory property of adrenomedullin. In macrophages and rat Kupffer cells, adrenomedullin has been shown to down-regulate tumour necrosis factor $\alpha$ release and gene expression [21]. The experimental studies by Koo et al. [22] suggest that exogenous adrenomedullin may also suppress IL-6 production in rats. In view of these findings, it is tempting to postulate that adrenomedullin may not only be useful to treat pulmonary hypertension, but that it could also be beneficial to protect against cardiovascular collapse originating from sepsis and systemic inflammatory response syndrome. This assumption is supported by the findings of YANG et al. [23], demonstrating that adrenomedullin infusion in rats reverses the moribund hypodynamic circulation to a more stable hyperdynamic circulatory state, thereby decreasing mortality. The bottom line is that, currently, in view of the published studies on this topic, relative adrenomedullin deficiency is implicated not only in the pathogenesis of pulmonary hypertension but also in circulatory failure secondary to systemic inflammation.

In summary, the study by VON DER HARDT et al. [13] in this issue of the $E R J$ supports the concept that nebulisation of adrenomedullin is a useful approach to treat pulmonary hypertension without affecting the systemic circulation. Since exogenous adrenomedullin also exhibits anti-inflammatory properties [13, 21, 22], reduces experimental microvascular leakage [24], and ameliorates both sepsis-associated cardiovascular dysfunction [23] and tissue dysoxia [10], adrenomedullin emerges as an interesting addition to the intensive care armentarium. Future studies investigating the safety and efficacy of adrenomedullin in humans with pulmonary hypertension and/or systemic inflammation are warranted.

\section{References}

1. Kitamura K, Kangawa K, Kawamoto M, et al. Adrenomedullin: a novel hypotensive peptide isolated from human pheochromocytoma. Biochem Biophys Res Commun 1993; 192: 553-560.

2. Hinson JP, Kapas S, Smith DM. Adrenomedullin, a multifunctional regulatory peptide. Endocr Rev 2000; 21: 138-167.

3. Kobayashi H, Itoh S, Yanagita T, Yokoo H, Sugano T, Wada A. Expression of adrenomedullin and proadrenomedullin N-terminal 20 peptide in PC12 cells after exposure to nerve growth factor. Neuroscience 2004; 125: 973-980.

4. Kitamura K, Kangawa K, Eto T. Adrenomedullin and PAMP: discovery, structures, and cardiovascular functions. Microsc Res Tech 2002; 57: 3-13.

5. Marutsuka K, Hatakeyama K, Sato Y, Yamashita A, Sumiyoshi A, Asada Y. Immunohistological localization and possible functions of adrenomedullin. Hypertens Res 2003; 26: S33-S40.

6. Michibata H, Mukuyama M, Tanaka I, et al. Autocrine/ paracrine role of adrenomedullin in cultured endothelial and mesangial cells. Kidney Int 1998; 53: 979-985.

7. Sakai K, Saito K, Ishizuka N. Adrenomedullin synergistically interacts with endogenous vasodilators in rats: a possible role of K(ATP) channels. Eur J Pharmacol 1998; 359: 151-159.

8. Yang BC, Lippton H, Gumusel B, Hyman A, Mehta JL. Adrenomedullin dilates rat pulmonary artery rings during hypoxia: role of nitric oxide and vasodilator prostaglandins. J Cardiovasc Pharmacol 1996; 28: 458-462.

9. Hayakawa H, Hirata Y, Kakoki M, et al. Role of nitric oxide-cGMP pathway in adrenomedullin-induced vasodilation in the rat. Hypertension 1999; 33: 689-693.

10. Kandler MA, Von der Hardt K, Mahfoud S, et al. Pilot intervention: aerosolized adrenomedullin reduces pulmonary hypertension. J Pharmacol Exp Ther 2003; 306: 1021-1026.

11. Beltowski J, Jamroz A. Adrenomedullin - what do we know 10 years since its discovery? Pol J Pharmacol 2004; 56: 5-27.

12. Westphal M, Stubbe H, Bone HG, et al. Hemodynamic effects of exogenous adrenomedullin in healthy and endotoxemic sheep. Biochem Biophys Res Commun 2002; 296: 134-138.

13. von der Hardt $\mathrm{K}$, Kandler MA, Chada M, et al. Brief adrenomedullin inhalation leads to a sustained reduction of pulmonary artery pressure. Eur Respir J 2004; 24: 615-623.

14. Nagaya Y, Okumara $\mathrm{H}$, Uematsu $\mathrm{M}$, et al. Repeated inhalation of adrenomedullin ameliorates pulmonary hypertension and survival in monocrotaline rats. Am J Physiol Heart Circ Physiol 2003; 285: H2125-H2131.

15. Nakanishi K, Osada H, Uenoyama M, et al. Expressions of adrenomedullin mRNA and protein in rats with hypobaric hypoxia-induced pulmonary hypertension. Am $J$ Physiol Heart Circ Physiol 2004; 286: H2159-H2168.

16. Nagaya $\mathrm{N}$, Nishikimi $\mathrm{T}$, Uematsu $\mathrm{M}$, et al. Haemodynamic and hormonal effects of adrenomedullin in patients with pulmonary hypertension. Heart 2000; 84: 653-658.

17. Nagaya N, Kyotani S, Uematsu M, et al. Effects of adrenomedullin inhalation on hemodynamics and exercise capacity in patients with idiopathic pulmonary arterial hypertension. Circulation 2004; 109: 351-306.

18. Eddahibi S, Adnot S. Endothelins and pulmonary hypertension, what directions for the near future? Eur Respir $J$ 2001; 18: 1-4.

19. Hanze J, Groneberg DA, Rose F, et al. Genomic organization and regulation of human 7-helix transmembrane receptor which is expressed in pulmonary epithelial cells and induced in hypoxia. Biochem Biophys Res Commun 2002; 291: $1160-1165$.

20. Booke M, Bradford DW, Hinder F, et al. Effects of inhaled nitric oxide and nebulized prostacyclin on hypoxic pulmonary vasoconstriction in anesthetized sheep. Crit Care Med 1996; 24: 1841-1148.

21. Wu R, Zhou M, Wang P. Adrenomedullin and adrenomedullin binding protein-1 downregulate TNF-alpha in macrophage cell line and rat Kupffer cells. Regul Pept 2003; 112: 19-26. 
22. Koo DJ, Yoo P, Cioffi WG, Bland KI, Chaudry IH, Wang P. Mechanism of the beneficial effects of pentoxifylline during sepsis: maintainance of adrenomedullin responsiveness and downregulation of proinflammatory cytokines. J Surg Res 2000; 91: 70-76.

23. Yang S, Zhou M, Chaudry IH, Wang P. Novel approach to prevent the transition from the hyperdynamic phase to the hypodynamic phase of sepsis: role of adrenomedullin and adrenomedullin binding protein-1. Ann Surg 2002; 236: 625633.

24. Ohbayashi H, Suito H, Yoshida N, Ilto Y, Kume H, Yamaki $\mathrm{K}$. Adrenomedullin inhibits ovalbumin-induced bronchoconstriction and airway microvascular leakage in guineapigs. Eur Respir J 1999; 14: 1076-1081. 